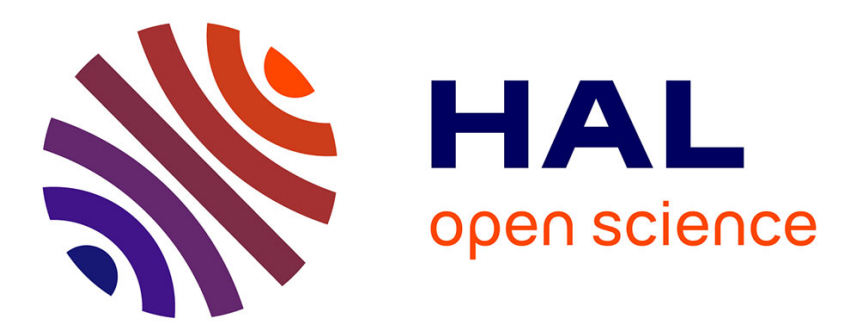

\title{
Multistep building of a soft plant protein film at the air-water interface
}

Alexandre Poirier, Amélie Banc, Antonio Stocco, Martin In, Laurence Ramos

\section{To cite this version:}

Alexandre Poirier, Amélie Banc, Antonio Stocco, Martin In, Laurence Ramos. Multistep building of a soft plant protein film at the air-water interface. Journal of Colloid and Interface Science, 2018, 526, pp.337 - 346. 10.1016/j.jcis.2018.04.087 . hal-01788790

\section{HAL Id: hal-01788790 \\ https://hal.science/hal-01788790}

Submitted on 9 May 2018

HAL is a multi-disciplinary open access archive for the deposit and dissemination of scientific research documents, whether they are published or not. The documents may come from teaching and research institutions in France or abroad, or from public or private research centers.
L'archive ouverte pluridisciplinaire HAL, est destinée au dépôt et à la diffusion de documents scientifiques de niveau recherche, publiés ou non, émanant des établissements d'enseignement et de recherche français ou étrangers, des laboratoires publics ou privés. 


\title{
Multistep building of a soft plant protein film at the air-water interface
}

\author{
Alexandre Poirier ${ }^{1}$, Amélie Banc ${ }^{1 *}$, Antonio Stocco ${ }^{1 *}$, Martin $\operatorname{In}^{1}$, Laurence Ramos $^{1}$ \\ ${ }^{1}$ Laboratoire Charles Coulomb (L2C), University of Montpellier, CNRS, \\ Montpellier, France.
}

\begin{abstract}
Alexandre.poirier@umontpellier.fr
Amelie.banc@umontpellier.fr

Antonio.stocco@umontpellier.fr

Martin.in@umontpellier.fr

Laurence.ramos@umontpellier.fr
\end{abstract}

\begin{abstract}
Gliadins are edible wheat storage proteins well known for their surface active properties. In this paper, we present experimental results on the interfacial properties of acidic solutions of gliadin studied over 5 decades of concentrations, from 0.001 to $110 \mathrm{~g} / \mathrm{L}$. Dynamic pendant drop tensiometry reveals that the surface pressure $\Pi$ of gliadin solutions builds up in a multistep process. The series of curves of the time evolution of $\Pi$ collected at different bulk protein concentrations $C$ can be merged onto a single master curve when $\Pi$ is plotted as a function of $\alpha t$ where $t$ is the time elapsed since the formation of the air/water interface and $\alpha$ is a shift parameter that varies with $C$ as a power law with an exponent 2 . The existence of such time-concentration superposition, which we evidence for the first time, indicates that the same mechanisms govern the surface tension evolution at all concentrations and are accelerated by an increase of the bulk concentration. The scaling of $\alpha$ with $C$ is consistent with a kinetic of adsorption controlled by the diffusion of the proteins in the bulk. Moreover, we show that the proteins adsorption at the air/water interface is kinetically irreversible. Correlated evolutions of the optical and elastic properties of the interfaces, as probed by ellipsometry and surface dilatational rheology respectively, provide a consistent physical picture of the building up of the protein interfacial layer. A progressive coverage of the interface by the proteins occurs at low $\Pi$. This stage is followed, at higher $\Pi$, by conformational rearrangements of the protein film, which are identified by a strong increase of the dissipative viscoelastic properties of the film concomitantly with a peculiar evolution of its optical profile that we have rationalized. In the last stage, at even higher surface pressure, the adsorption is arrested; the optical profile is not modified while
\end{abstract}


the elasticity of the interfacial layer dramatically increases with the surface pressure, presumably due to the film ageing.

Key words: Gliadin, soft plant protein, air-water interface, tensiometry, dilatational rheology, ellipsometry, master curve, conformational change.

\section{Introduction}

Interfacial properties govern many structural and mechanical properties of bulk materials and dispersions. Common examples include the importance of grain-boundaries in the mechanical properties of atomic, molecular and colloidal polycrystals, and of surface actives species in stabilizing foams and emulsions, thanks to their adsorption at air/liquid or liquid/liquid interfaces ${ }^{1}$. Characterizing in details those liquid interfaces is the key to understand and possibly tune the bulk properties of foams and emulsions, which are crucial in a wide range of industrial applications from cosmetics to agrochemistry and pharmacy. There is a wealth of surface active species (e.g. soaps, phospholipids and polymer molecules with different architectures) that spontaneously adsorb at a liquid interface. Proteins, which are amphiphilic compounds made of polar and non-polar amino acid residues, also tend to accumulate at air/water and oil/water interfaces. Understanding and controlling the interfacial adsorption of proteins is important in many industrial fields from food science, to purification and implantable medical devices, for instance. Proteins films are usually characterized by a high viscoelasticity and can undergo a glass or gel transition due to a protein crowding at the interface even for low bulk concentrations of the subphase ${ }^{2}$. Up to now, the majority of detailed studies on interfacial properties of protein films has been conducted with animal proteins. Many works focused on bovine serum albumin, $\beta$-lactoglobulin and ovalbumin, which are globular proteins considered as hard proteins, and on $\beta$-casein, which is considered as a soft protein prone to conformational changes at the interface and yielding softer interfaces than hard proteins ${ }^{3}$.

Interfacial properties of plant proteins have been much less investigated than their animal counterpart ${ }^{4}$. Among vegetable proteins, wheat storage proteins, commonly known as gluten proteins, represent an important part of the occidental people diet. Indeed, many food products traditionally contain wheat flour. In addition, gluten is also used as a texturing agent by the food industry that exploits the unique properties of the viscoelastic network created by these proteins. The interfacial properties of these proteins were also explored to better understand their role in the gas holding capacity of dough, and to determine their potentiality for the development of new products ${ }^{5}$. These studies were performed on either whole gluten proteins ${ }^{6}$ or separately on the two main classes of gluten proteins: glutenins, the polymeric proteins, and gliadins, the monomeric ones. Gluten proteins are non-globular proteins that behave as polymers and 
display a persistence length similar to that of disordered proteins ${ }^{7}$. Their secondary structure is labile and depends of the environment ${ }^{8}$ and osmotic pressure ${ }^{9}$. It was established that gliadins are more surface active than glutenins ${ }^{10}$ and display at equilibrium lower surface tension at the air-water interface than soy glycinin, casein ${ }^{11}$ or bovine serum albumin proteins ${ }^{12}$. Furthermore, gliadins were demonstrated to be very surface active for oil-water interfaces and form highly viscoelastic films ${ }^{4 a}$. As a consequence, gliadins were studied to stabilize foams ${ }^{10 a}, 13$ and emulsions ${ }^{12}$. However, the precise mechanism of gliadin adsorption at interface, the structure of the film formed and its rheology are still not well described.

In the present work, we investigate the adsorption of gliadins at the air-water interface from acidic solutions displaying a large range of concentration of proteins, from $1 \mathrm{mg} / \mathrm{L}$ to $110 \mathrm{~g} / \mathrm{L}$. Solutions are prepared at acidic $\mathrm{pH}$, for which gliadins are the most soluble in aqueous solvent due to their neutral isoelectric point. A combination of tensiometry, dilatational viscoelasticity and ellipsometry measurements is performed as a function of time. A time-concentration superposition is evidenced whatever the subphase concentration and reveals that protein adsorption at the interface is dominated by bulk diffusion. We propose a consistent physical picture of the multistep diffusion-controlled irreversible adsorption of the gliadin proteins at an air/water interface, and discuss our main conclusive results in light of the literature. Overall all our experimental results indicate that gliadin displays a behavior typical of soft proteins.

\section{Material and methods}

\subsection{Material}

\section{Gliadin extraction and characterization}

Gliadins are extracted from industrial gluten (courtesy of Tereos Syral, France) according to a protocol previously described by some of us $^{7}$. Briefly, gluten powder is mixed with $50 \%(\mathrm{v} / \mathrm{v})$ ethanol/water solvent and submitted to a continuous rotating agitation for 19 hours. After centrifugation, the supernatant is recovered and placed at $4{ }^{\circ} \mathrm{C}$ to induce a liquid-liquid phase separation. The light phase, enriched in gliadins, is recovered and freeze-dried. This fraction (labelled S2 in Ref. ${ }^{7}$ ) is characterized by Sodium Dodecyl Sulfate PolyAcrylamide Gel Electrophoresis, SDS-Page) and size-exclusion high performance liquid chromatography (SE-HPLC). Figure 1a displays the SE-HPLC profile measured on a TSK G400 SWXL column using the experimental conditions described in Dahesh et al. ${ }^{14}$. The molecular weight $\left(M_{\mathrm{w}}\right)$ 
composition deduced from the profile is $78 \%$ gliadins $\left(25000<M_{\mathrm{w}}<55000 \mathrm{~g} / \mathrm{mol}\right)$, $15 \%$ glutenins $\left(60000<M_{\mathrm{w}}<400000 \mathrm{~g} / \mathrm{mol}\right)$ and $7 \%$ albumins-globulins $\left(M_{\mathrm{w}} \approx 20000 \mathrm{~g} / \mathrm{mol}\right)$.

\section{Sample preparation}

We use a $50 \mathrm{mM}$ acetic acid aqueous solvent (purity 99\%) $(\mathrm{pH}=3)$ to fully solubilize gliadin proteins (gliadins are insoluble at neutral $\mathrm{pH}$ ). Protein/solvent mixtures of concentration $C=50 \mathrm{~g} / \mathrm{L}$ and higher are put in a rotary shaker overnight at room temperature to allow sample homogenization. They are subsequently filtered with a $0.22 \mu \mathrm{m}$ cellulose mixed ester membrane. Diluted solutions are prepared from the stock solution at $C=50 \mathrm{~g} / \mathrm{L}$ by dilution with $50 \mathrm{mM}$ acetic acid aqueous solvent to reach the target concentrations.

\section{Bulk sample characterizations}

\section{$\underline{\text { Size of the proteins }}$}

The hydrodynamic radius of the proteins in a acetic acid solution $(50 \mathrm{mM})$ is characterized by dynamic light scattering (DLS) performed at a wavelength $\lambda=532 \mathrm{~nm}$ for 6 different scattering angles ranging between 40 and $120^{\circ}$. The number size distribution is dominated by objects with a hydrodynamic radius of $5 \mathrm{~nm}$. This size is consistent with the radius of gyration of gliadins $(3<R \mathrm{~g}<5 \mathrm{~nm})$ measured by Thomson et al. ${ }^{15}$ who modeled gliadins as prolate ellipsoids with an aspect ratio comprised between 4 and 6 . We expect that the interfacial properties, as measured in this study, are majorly due to individual gliadins.

\section{Dielectric constant and refractive index}

The refractive index of the protein solutions in the visible range, $n_{\text {bulk }}$, is measured with an Abbe refractometer, for protein concentrations $C$ from 0 to $50 \mathrm{~g} / \mathrm{L}$. Concentrations are converted in volume fraction of dry protein, $\phi_{\mathrm{B}}$, assuming a protein relative density $\rho=1.32^{16}$. For $\phi_{\mathrm{B}}$ in the range $(0-0.038)$, the data can be very well accounted for by a linear variation of $n_{\text {bulk }}^{2}$ with the volume fraction of proteins $\phi_{\mathrm{B}}$ (Fig. 1b) as predicted theoretically. In the Wiener effective medium approximation ${ }^{17}$, the dielectric constant $\varepsilon=n^{2}$ (with $n$ the refractive index) is indeed expected to change linearly with $\phi_{B}$. Hence the refractive index of the protein solutions, $n_{\text {bulk }}$, reads

$n_{\text {bulk }}^{2}\left(\phi_{B}\right)=n_{\text {solv }}^{2}\left(1-\phi_{\mathrm{B}}\right)+n_{\text {prot }}^{2} \phi_{B}$

with $n_{\text {solv }}=1.333$ the index of refraction of the solvent, and $n_{\text {prot }}$ the index of refraction of the proteins. Equation 1 can be rewritten as

$n_{\text {bulk }}^{2}\left(\phi_{B}\right)=n_{\text {solv }}^{2}+\phi_{B}\left(n_{\text {prot }}^{2}-n_{\text {solv }}^{2}\right)=n_{\text {solv }}^{2}+\frac{\Delta\left(n^{2}\right)}{\Delta \phi} \phi_{B}$ 
The best fit of the experimental data with Equation 2 yields $\frac{\Delta\left(n^{2}\right)}{\Delta \phi}=0.599$, giving an index of refraction of the proteins, $n_{\text {prot }}=\sqrt{n_{\text {solv }}^{2}+\frac{\Delta n^{2}}{\Delta \phi}}=1.541$. This value is consistent with the literature $(n=1.555$ was found for gliadins in $0.1 \mathrm{M}$ acetic acid solution) $)^{18}$.

\subsection{Pendant drop tensiometry and dilatational rheology}

\section{Pendant drop tensiometry}

A drop profile analysis tensiometer (PAT-1, SINTERFACE Technologies, Germany) is used for surface tension and surface dilatational rheology measurements. An aqueous drop (typical volume $15 \mathrm{~mm}^{3}$ ) is formed at the capillary tip inside an empty measuring glass cell. The images of the drop are recorded and the interfacial tension is computed from the drop shape ${ }^{19}$. The surface pressure is defined as $\Pi=\gamma_{\text {solv }}-\gamma$, where $\gamma_{\text {solv }}$ is the surface tension of the acetic acid aqueous solvent in absence of protein and $\gamma$ is the surface tension of the protein solution against air.

\section{Droplet washing}

To assess the reversible character of adsorption, we use the drop profile tensiometer with a coaxial capillary to form a drop and subsequently wash the inside of the drop by replacing a volume $\Delta V=1 \mathrm{~mm}^{3}$ of the interior of the drop by pure solvent. This step lasts about 1s. To ensure a complete washing of the drop this procedure is repeated 450 times, so that the total volume exchanged is thirty times that of the drop (15 $\mathrm{mm}^{3}$ ). The time evolution of the surface tension, before, during and after the washing procedure is measured.

\section{Dilatational rheology measurements}

We use the drop profile tensiometer to study the dilatational rheology of proteins at the air-water interface. To do so, an aqueous drop is perturbed by small harmonic oscillations of the interfacial area $A$ leading to harmonic oscillations of the surface tension $\gamma$. From the Fourier transform $F$ of the response relative to the perturbation the complex visco-elastic modulus $E$ is calculated ${ }^{19}$ :

$E(i \omega)=\frac{F[\Delta \gamma]}{F[\ln (\Delta A)]}$

where the real part, $E$, is the storage modulus that characterizes the dilatational interfacial elasticity, and the imaginary part, $E$, is the loss modulus and is related to the dilatational interfacial viscosity. We impose relative deformations $\frac{\Delta A}{A}$ of $5 \%$, respectively $10 \%$, at a frequency of $0.025 \mathrm{~Hz}$, respectively $0.05 \mathrm{~Hz}$, 
for samples with bulk concentrations below, respectively above, $50 \mathrm{mg} / \mathrm{ml}$. These parameters are chosen to optimize the quality of raw data while remaining in the linear regime of the response.

\subsection{Wilhelmy plate tensiometry, ellipsometry and Brewster angle microscopy}

Planar interfaces are characterized using a set-up that combines a Wilhelmy plate (KSV, Nima), a Brewster angle microscope (Optrel, Germany) and an ellipsometer (Optrel, Germany). The time evolution of the air-water interface is probed after a glass Petri dish of $17 \mathrm{~cm}$ diameter has been filled with protein solutions.

On the one hand, Brewster angle images are recorded using the ellipsometric device equipped with a 10X magnification objective and an acquisition camera. The contrast of the images is controlled by rotating the polarizer angle, the analyzer angle being kept constant (vertically polarized).

On the other hand, the optical profile and surface excess concentrations $\Gamma$ of proteins at the air/water interface are measured by ellipsometry. $\Gamma$ is defined as:

$\Gamma=\int_{-\infty}^{0}(C(z)-C) d z+\int_{0}^{+\infty} C(z) d z$

Here $z$ is the axis normal to the interface (with the convention $z>0$ in air) and $z=0$ is the location of the Gibbs dividing surface, $C(z)$ is the solute concentration as a function of the distance $z$ from the interface and $C$ the solute concentration in the bulk solution $[C=C(z \ll 0)]$.

An ellipsometer working with a green laser light $(\lambda=533 \mathrm{~nm})$ is used to measure the quantities $\Psi$ and $\Delta$. Measurements are performed at the incident angle $\varphi_{\text {air }}=55^{\circ} . \Psi$ and $\Delta$ are related to the ratio of reflection field coefficients $\frac{r_{p}}{r_{s}}$ by:

$\frac{r_{p}}{r_{s}}=\tan \Psi \exp i \Delta$

Here $r_{p}$ is the component of field reflection coefficient parallel to the reflection plane, and $r_{s}$ is the component perpendicular to reflection plane. Data are analyzed in the framework of perturbation theory, which describes $\frac{r_{p}}{r_{s}}$ as the deviation from the reflection coefficient $\frac{r_{p, 0}}{r_{s, 0}}$ expected for a sharp step-like profile $^{20}$ :

$\frac{r_{p}}{r_{s}}=\frac{r_{p, 0}}{r_{s, 0}}+\frac{2 i Q_{a i r}}{r_{s, 0}\left(Q_{a i r}+Q_{\text {bulk }}\right)^{2}} \frac{K^{2}}{n_{\text {air }}^{2} n_{\text {bulk }}^{2}} I_{1}$ 
Here $Q_{\text {air }}=2 \pi /\left(n_{\text {air }} \lambda\right) \cos \varphi_{\text {air }}, Q_{\text {bulk }}=2 \pi /\left(n_{\text {bulk }} \lambda\right) \cos \varphi_{\text {bulk }}$ and $K=2 \pi n_{\text {air }} / \lambda \sin \varphi_{\text {air }}$, where $n_{\text {air }}$, and $n_{\text {bulk }}$ are the refractive index of air and the bulk liquid phase; and $\varphi_{\text {air }}$ and $\varphi_{\text {bulk, }}$ are the angles related by the Snell's law: $n_{\text {air }} \sin \varphi_{\text {air }}=n_{\text {bulk }} \sin \varphi_{\text {bulk }}$. The term $I_{l}$ is related to the interfacial optical profile $\operatorname{as}^{20}$ :

$I_{1}=\int_{-\infty}^{+\infty}\left[\frac{\left(\epsilon_{\perp}(z)-\epsilon_{\text {air }}\right)\left(\epsilon_{\perp}(z)-\epsilon_{\text {bulk }}\right)}{\epsilon_{\perp}(z)}+\left(\epsilon_{\|}-\epsilon_{\perp}\right)\right] d z$

Here $\epsilon_{\|}$, respectively $\epsilon_{\perp}$, is the component of the dielectric constant parallel, respectively perpendicular, to the interface, and $\epsilon_{i}=n_{i}^{2}$.

If the interfacial layer is locally isotropic, $\epsilon_{\|}=\epsilon_{\perp}=\epsilon_{L}$, and Equation 7 reads

$I_{1}=\int_{-\infty}^{+\infty} \frac{\left(\epsilon_{L}(z)-\epsilon_{\text {air }}\right)\left(\epsilon_{L}(z)-\epsilon_{\text {bulk }}\right)}{\epsilon_{L}(z)} d z$

In the limit of optically thin interfacial layers, $I_{1}$ is related to the surface excess concentration measured by ellipsometry $\Gamma_{\text {elli }}$, which is approximately equal to the surface excess concentration $\Gamma$ (Eq. 4):

$I_{1} \cong \Gamma_{\epsilon} \int_{-\infty}^{+\infty} \frac{\left(\epsilon_{L}(z)-\epsilon_{\text {air }}\right)}{\epsilon_{L}(z)} d z \cong \Gamma_{\epsilon} \frac{\epsilon_{\text {bulk }}-\epsilon_{\text {air }}}{\epsilon_{\text {bulk }}}$

where $\Gamma_{\epsilon}=\int_{-\infty}^{\infty}\left(\epsilon_{L}(z)-\epsilon_{\text {bulk }}\right) d z$ gives in a good approximation the dielectric constant surface excess. Finally, the surface excess concentration reads ${ }^{21}$ :

$\Gamma \cong \Gamma_{e l l i}=\frac{\Gamma_{\epsilon}}{\Delta \epsilon / \Delta C}=\cong \frac{I_{1} \frac{\epsilon_{\text {bulk }}}{\epsilon_{\text {bulk }}-\epsilon_{\text {air }}}}{\Delta \epsilon / \Delta C}$

\section{Experimental results}

\subsection{Surface tension.}

We show in Figure 2a the time evolution of the air/water surface tension, $\gamma$, measured for several protein concentrations $C$ in the aqueous phase, spanning more than 5 orders of magnitude (from 0.01 to $110 \mathrm{~g} / \mathrm{L}$ ), over a time scale ranging from $5 \mathrm{~s}$ to $10000 \mathrm{~s}$, using the pendant drop tensiometry. We find that the surface tension of the solvent is constant $\left(\gamma_{\mathrm{solv}} \approx 73 \mathrm{mN} / \mathrm{m}\right)$ over the whole duration of the measurements, ensuring reliable data over the full time scale. For the lowest protein concentration $(0.01 \mathrm{~g} / \mathrm{L})$, an induction 
period of about $50 \mathrm{~s}$ is observed during which the surface tension of the protein solution stays constant and equal to that of the solvent and then continuously decreases with time. For the other protein concentrations the induction period is too short to be measured with our experimental set-up. We find indeed that the surface tension at the shortest accessible time is systematically smaller than that of the solvent and decreases with the protein concentration. Note that several regimes of surface tension decrease with time can be identified in a semi-log scale.

Interestingly, all the data acquired for $\mathrm{C}>0.1 \mathrm{~g} / \mathrm{L}$, overlap on a single master curve once plotted as a function of a normalized time $\alpha t$, where $t$ is the real time elapsed since the drop formation and $\alpha$ is a scale factor. We arbitrarily choose $C=1 \mathrm{~g} / \mathrm{L}$ as the reference concentration $(\alpha=1)$. The scaling is shown in Figure $2 \mathrm{~b}$ where the surface pressure $\Pi$, is plotted as a function of $\alpha t$. The master curve evidences two exponential growths of the surface pressure associated with characteristic times $\alpha t_{1}=500 \mathrm{~s}$ and $\alpha t_{2}=19000$ s (fits not shown) followed by asymptotic logarithmic evolution. The scaling does not hold for the two lowest protein concentrations $(0.01$ and $0.1 \mathrm{~g} / \mathrm{L})$. For these dilute solutions, the drop (typical volume 15 $\mathrm{mm}^{3}$ ) does not constitute an infinite reservoir of protein, and the dynamic surface tension is expected to be strongly influenced by the depletion of proteins in the bulk due to their adsorption at the interface ${ }^{22}$. To overcome this problem and complete our experimental data in the low concentration limit, we perform similar measurements with a planar geometry, for bulk protein concentrations between $0.001 \mathrm{~g} / \mathrm{L}$ and $10 \mathrm{~g} / \mathrm{L}$. In these conditions, a regime of infinite reservoir of proteins is systematically reached. We use a Petri dish filled with the protein solution and measure the surface tension as a function of time using a Wilhelmy plate. A master curve, surface pressure versus rescaled time $\alpha t$, similar to that obtained in the pendant drop experiment, is also obtained. The scaling factors, $\alpha$, used to build master curves with the experimental data collected in the two experimental geometries are displayed in Figure 2c. We find that $\alpha$ increases as a power law of the concentration, $\alpha \sim C^{p}$ with $p=1.9$. We note that this value is close to 2 , the numerical value expected for a diffusive process. This point will be discussed below.

To address the reversibility of gliadin adsorption we measure the time evolution of the surface pressure after dilution of the bulk subphase. In the case of reversible adsorption, a decrease of the bulk concentration should lead to a decrease of the surface pressure ${ }^{23}$. This has been checked with a soluble surfactant (dodecyltrimethylammonium chloride, DTAC), ensuring the reliability of our experimental procedure (as detailed in the Materials and methods section). By contrast, in the case of gliadin, $\Pi$ never decreases after washing, as shown in Figure 3. Three experiments carried out at different stages of the time evolution of the surface pressure are presented. At low surface pressures $(\Pi=11 \mathrm{mN} / \mathrm{m}$ and $\Pi=21$ $\mathrm{mN} / \mathrm{m}$ ), dilution of the bulk does not lead to any significant decrease of the surface pressure, although it dramatically reduces the rate of increase of the surface pressure. At high pressure $(\Pi=30 \mathrm{mN} / \mathrm{m})$ dilution 
of the bulk turns out to have no effect on the increase rate of the surface pressure. Thus, our findings indicate that, at low pressure the evolution of $\Pi$ is determined by protein transfer from the bulk to the interface, while at high pressure the further evolution of the pressure is independent of mass transfer to the interface. Moreover, since no decrease of the surface pressure could be evidenced, the desorption of the protein from interface is certainly extremely slow if ever it occurs. Adsorption of gliadins at interface can thus be safely considered as irreversible.

\subsection{Dilatational viscoelasticity of the protein interfacial layer}

We measure the dilatational viscoelasticity of the interfacial layer at different times after the drop formation and for various protein concentrations in the subphase. We find that the viscoelastic measurements only depend on the surface pressure of the interface and that data collected at different protein concentrations (from $6.5 \mathrm{mg} / \mathrm{L}$ to $800 \mathrm{mg} / \mathrm{L}$ ) reasonably fall onto a single master curve (Fig. 4). In the whole range of surface pressure investigated $(5 \mathrm{mN} / \mathrm{m}<\Pi<40 \mathrm{mN} / \mathrm{m})$, the interfacial protein layer is essentially elastic with an elastic modulus, E', always larger than the loss modulus, $E^{\prime \prime}$. The elastic modulus varies non-monotonically with the surface pressure, and three regimes can be defined for the $(E$ ' vs $\Pi$ ) master curve. In regime I, $\Pi<\Pi_{\mathrm{c} 1} \approx 19 \mathrm{mN} / \mathrm{m}$, and regime III, $\Pi>\Pi_{\mathrm{c} 2} \approx 31 \mathrm{mN} / \mathrm{m}, E^{\prime}$ continuously increases with surface pressure, whereas in the intermediate regime $\left(\Pi_{\mathrm{c} 1}<\Pi<\Pi_{\mathrm{c} 2}\right), E^{\prime}$ decreases and reaches a minimum with $\Pi$. Interestingly the minimum of $E$ ' with the surface pressure is accompanied by a large increase of the loss modulus (Fig. 4b): the ratio $E^{\prime \prime} / E$ ' reaches about 0.4 in regime II, whereas this ratio is of the order of $(0.1-0.15)$ in regimes I and III. Furthermore, it is worth mentioning that, in the intermediate regime, the collapse of the data collected at different protein concentrations is not as good as in the two other regimes, but instead the maximum of $E^{\prime \prime} / E^{\prime}$ seems to increase with $C$. The limits of these three regimes are also reported on the tensiometry plot that displays washing test in each regime (Figs. 3).

\subsection{Optical properties of the protein interfacial layer.}

The structure of the interfacial protein films prepared in Petri dishes is observed by Brewster angle microscopy. Figure 5b displays characteristic images obtained for the 3 different regimes of surface pressure and viscoelasticity defined above. In all cases, the films appear very homogeneous at the microscopic scale. To get pictures with a good contrast it is necessary to adjust the polarizer angle from $0^{\circ}$ 
to $15^{\circ}$. The increase of the brightness with surface pressure indicates an increase of surface reflectivity that we associate to an increase of the amount of proteins at the interface.

In order to quantitatively characterize the optical properties of the interfacial layer we use ellipsometry. Similarly to our findings for the viscoelastic properties, we measure that the structure of the interfacial layer only depends on the surface pressure and that data acquired at different protein concentrations for the subphase (in the range 0.001 to $5 \mathrm{~g} / \mathrm{L}$ ) collapse on a single curve (Fig. $5 \mathrm{a}$ ). The ellipsometric signal, $I_{1}$, varies non-monotonically with $\Pi$, which allows distinguishing the same three regimes as before with the same cross-over pressures $\Pi_{\mathrm{c} 1}$ and $\Pi_{\mathrm{c} 2}$. In regime $\mathrm{I}, I_{1}$ increases with $\Pi$, whereas $I_{1}$ decreases with $\Pi$ in regime II, and is more or less constant in regime III. In addition, we also observe a preliminary regime in which $I_{1}$ increases in time whereas the surface pressure is maintained at zero.

\section{Discussion}

We have investigated the interfacial properties of acidic solutions of gliadin studied over 5 decades of concentrations from 0.001 to $110 \mathrm{~g} / \mathrm{L}$. Gliadins adsorb irreversibly at the air-water interface in accordance with other studies on proteins ${ }^{24}$. The structural and viscoelastic properties of the interfacial gliadin film build up in a multistep process, the evolution of which is completely characterized by the surface pressure. The master curves obtained for the surface pressure, the viscoelasticity and the optical properties of the interfacial layer indicate that the properties at the air/water interface are determined by the concentration of the subphase and the time elapsed since the formation of the interface.

\section{$\underline{4.1 \text { Adsorption kinetics }}$}

For low surface pressures, $\Pi<\Pi_{\mathrm{c} 1}$, the optical profile is assumed to be locally isotropic (and equations 8 10 hold) because of the weak interaction between proteins, which are randomly oriented at the interface. We determine the surface excess concentration $\Gamma$ according to Equation 10. Figure 6a displays the evolution of $\Gamma$ as a function of time for three different concentrations, and for two sets of data for each concentration. We measure that the higher is the bulk concentration, the faster is the adsorption. Experimental data can be compared to an analytical model of diffusion-controlled adsorption kinetics ${ }^{25}$ :

$\Gamma(t)=\Gamma_{m}-\Gamma_{m} \exp \left(-2 C / \Gamma_{m} \sqrt{\frac{D t}{\pi}}\right)$

With $D$ the bulk protein diffusion coefficient and $\Gamma_{m}$ the maximum surface excess concentration. Equation 11 takes into account the decreasing difference of chemical potential of the proteins between bulk and interface along the adsorption process ${ }^{26}$. Hence at longer time and higher concentration, a steady state is 
reached with this model that takes into account saturation. Far from interface saturation on the other hand, when the chemical potential at interface can reasonably be considered as being constant, hence at short time and low concentration ${ }^{27}$, Equation 11 can be approximated as

$$
\Gamma(t)=2 C \sqrt{\frac{D t}{\pi}}
$$

and

Note that equation 12 is the short time limit of the Ward and Tordai model ${ }^{28}$ that is classically used to model interfacial adsorption of surface active components. However, we do not use this model because it considers an instantaneous equilibrium of adsorbing species between the bulk and the interface and allows thus for back-diffusion which we have demonstrated to be negligible for gliadin at the air-water interface. The theoretical curves presented in the figure 6a are calculated using the bulk diffusion coefficient measured by dynamic light scattering and the maximum surface excess concentration measured at the end of regime I $\left(D=4.4110^{-11} \mathrm{~m}^{2} / \mathrm{s}\right.$ and $\left.\Gamma_{m}=3.1 \mathrm{mg} / \mathrm{m}^{2}\right)$ and quantitatively compared to the experimental data. Overall a good agreement is found between the theoretical expectations and the experimental results (Fig. 6a). Equation 12 account nicely for the experimental data measured at $C=0.001 \mathrm{~g} / \mathrm{L}$. Experimental data with $C=0.01 \mathrm{~g} / \mathrm{L}$ and $C=0.1 \mathrm{~g} / \mathrm{L}$ are instead better described taking into account a saturation (Eq. 11).

\subsection{Surface pressure master curve: Time-concentration superposition}

In line with those results, a time-concentration superposition is clearly evidenced, for the first time, to the best of our knowledge, for proteins at a liquid interface. It indicates that interfacial measurements performed with solutions at high protein concentration can predict the long ageing time behavior of interfaces formed from solutions at lower concentrations. The existence of a master curve furthermore indicates that the surface pressure obtained with a bulk concentration $C$ and an elapsed time $t$ can also be obtained with the reference concentration, $C_{r e f}$, with an elapsed time $t_{r e f}$ :

$\Pi(C, t)=\Pi\left(C_{r e f}, t_{r e f}\right)$

with $t_{r e f}=\alpha t$

With the assumption that only one surface concentration, $\Gamma$, is associated to a given surface pressure, $\Pi$, one can also write

$$
\Gamma(C, t)=\Gamma\left(C_{\text {ref }}, t_{\text {ref }}\right)
$$

According to the time evolution of the surface excess concentration in regime I, we have shown that the protein adsorption is controlled by diffusion. Combining the diffusion-controlled models previously introduced (Eqs. 11 and 12) with Equations 14 and 15, one derives the value of the scaling factor $\alpha$ :

$\alpha=\left(\frac{C}{c_{\text {ref }}}\right)^{2}$ 
Figure $2 \mathrm{c}$ shows that the theoretical prediction (Eq. 16) with $C_{r e f}=1 \mathrm{~g} / \mathrm{L}$ fits very nicely the experimental data over a 4 orders of magnitude for the protein bulk concentration (from 0.001 to $10 \mathrm{~g} / \mathrm{L}$ ). These concentrations cover regimes I and II, for which we have demonstrated, thanks to the droplet washing procedure, that the evolution of the interfacial pressure is mainly associated to protein adsorption. We mention that in the literature ${ }^{29}$, the diffusion-controlled models were restricted to dilute regimes. Ybert and di Meglio $^{29 a}$ previously performed a time-concentration rescaling of tensiometry data for bovine serum albumin at an air/water interface but were puzzled by the correspondence between curves at high surface pressure as they expected dynamics to be governed by adsorption mechanisms. In the case of gliadins the adsorption of additional proteins to an already relatively dense interface appears not to be the limiting step, even when the protein concentration at the interface is relatively large (excess surface concentration $>3 \mathrm{mg} / \mathrm{m}^{2}$ ). We think that the diffusive protein mass transfer remains possible thanks to the creation of free space at the interface with the reorganization of proteins previously adsorbed due to the protein crowding. So, the propensity of gliadins to easily reorganize at interfaces could explain this behavior. In line with our physical picture, Miura et $\mathrm{al}^{30}$ showed by simulations that the overall adsorption kinetics of chain molecules on a surface is not strongly affected by their internal reorganization. They rationalized their result using a theoretical model that considers bulk diffusion, Langmuir adsorption and rearrangement of anisotropic molecules through a second order reaction.

On the other hand, for higher concentrations, we measure that $\alpha$ is smaller than theoretically expected for a diffusive process, showing that the increase of bulk protein concentration does not speed up the time evolution of the surface pressure as much as expected for a purely diffusion-controlled process. For these concentrations, the shift factor is determined according to surface tension profiles dominated by the regime III that is very rapidly reached. In this regime, the drop washing test showed that adsorption is not involved, explaining the discrepancy between $\alpha$ determined at high concentration and the model. Overall, we show that the surface tension dynamics is controlled by bulk diffusion of gliadin toward the air-water interface at short times (low surface pressures), during regime I, but also during regime II.

\section{$\underline{4.3 \text { Surface excess concentration and protein conformational changes by ellipsometry }}$}

Thanks to the concomitant measurement of the surface pressure and surface excess concentration, the surface pressure isotherm of gliadin proteins at the air-water interface, $\Pi$ versus $\Gamma$, can also be plotted for $\Pi<\Pi_{\mathrm{c} 1}$ (Fig. 6b). In the early regime, below $\Gamma_{0}=0.5 \mathrm{mg} / \mathrm{m}^{2}$ (which corresponds to a surface of $116 \mathrm{~nm}^{2}$ occupied on average by each protein), no evolution of the surface pressure could be measured due to the high molecular weight of the surface active species. According to the ideal gas law a very weak dependence of the surface pressure with the surface excess concentration is predicted in this concentration range: $\Pi=R T \Pi M_{\mathrm{w}}$, with $R$ the ideal gas constant, $T$ the temperature and $M_{\mathrm{w}}$ the molecular weight of the 
species adsorbed at the interface. For objects with $M_{\mathrm{w}}=35000 \mathrm{~g} / \mathrm{mol}$ (Fig. 1), one predicts $\Pi=0.07 \Gamma$, i.e. a surface pressure of $3.510^{-2} \mathrm{mN} / \mathrm{m}$ for $\Gamma_{0}=0.5 \mathrm{mg} / \mathrm{m}^{2}$. Such low value is not measurable with our technique (see line of the ideal gas law in Fig. 6).

For $\Gamma>\Gamma_{0}$, the surface pressure increases faster with the surface concentration as a result of proteins interactions. The pressure increases linearly with $\Gamma$ up to a value of $\Gamma_{\max }=3.1 \mathrm{mg} / \mathrm{m}^{2}$ that we considered as the saturation. Modeling the protein layer as a monolayer of hard spheres of constant thickness $h$, at maximal packing, the protein volume fraction at interface is $\phi_{L}=0.6$. Using $\Gamma=\rho h \phi_{L}$ at saturation, with the protein relative density $\rho=1.32$, we find that the thickness of the film is $h=4 \mathrm{~nm}$. This value is consistent with the size of gliadins, as measured by dynamic light scattering. The preliminary regime, characterized by a negligible surface pressure, corresponds to a gas regime in which proteins adsorb on a nearly "free interface" whereas in the regime I proteins adsorb on an interface already covered by interacting proteins.

In regime II, the ellipsometric signal $I_{1}$ decreases while the surface pressure increases. In this regime, equations 8-10 do not hold anymore because the surface concentration cannot decrease if the surface pressure increases. In the absence of desorption, such behavior can only be accounted for by a conformational change of the interfacial layer. Hypotheses of formation of chain loops or multilayer in the bulk can be safely discarded as such processes would lead to constant or increasing $I_{1}$ according to equation 8. Partial protein dehydration or the development of an anisotropic refractive index in the interfacial layer is instead consistent with the decrease of $I_{1}$ as detailed below.

In the hypothesis of a progressive dehydration and protrusion of proteins in air, equation 9 cannot be used. A two-step dielectric constant profile for the protein film with a constant thickness $h$ is assumed. We define $\psi_{\text {air }}$ as the fraction of the thickness of the interfacial protein film in air. The protein film is therefore decomposed into the sum of a layer of thickness $h \psi_{\text {air }}$ in air, and a layer of thickness $h$ (1$\left.\psi_{\text {air }}\right)$ in the solvent. Equation 8 thus becomes

$I_{1}=I_{1}^{\text {air }}+I_{1}^{\text {solv }}$

with

$I_{1}^{\text {air }}=\frac{\left(n_{\text {protair }}^{2}-n_{\text {air }}^{2}\right)\left(n_{\text {protair }}^{2}-n_{\text {bulk }}^{2}\right)}{n_{\text {protair }}^{2}} \psi_{\text {air }} h$

and

$I_{1}^{\text {solv }}=\frac{\left(n_{\text {protsolv }}^{2}-n_{\text {air }}^{2}\right)\left(n_{\text {protsolv }}^{2}-n_{\text {bulk }}^{2}\right)}{n_{\text {protsolv }}^{2}}\left(1-\psi_{\text {air }}\right) h$

Here, $n_{\text {air }}$ is the index of refraction of air, $n_{\text {bulk }}$ is the index of refraction of the subphase, as measured experimentally (Eqs. 1\&2). $n_{\text {protair }}$, respectively $n_{\text {protsolv }} \mathrm{y}$, is the index of refraction of the protein layer in air, respectively solvent. Following Equation 2, 
$n_{\text {protair }}^{2}=n_{\text {air }}^{2}+\phi_{L}\left(n_{\text {prot }}^{2}-n_{\text {air }}^{2}\right)$

and

$n_{\text {protsolv }}^{2}=n_{\text {solv }}^{2}+\phi_{L}\left(n_{\text {prot }}^{2}-n_{\text {solv }}^{2}\right)$

with $\phi_{L}$ the volume fraction of proteins in the interfacial layer. Whatever $\phi_{L}, I_{1}^{\text {air }}<I_{1}^{\text {solv }}$. As a consequence, the decrease of $I_{1}$ observed in regime II could be accounted by an increase of $\psi_{\text {air }}$ and associated to protein dehydration. Considering $\phi_{L}=0.6$ and $h=4 \mathrm{~nm}$ (the numerical values found at the end of regime I), we estimate that $\psi_{\text {air }}$ continuously increases in regime II and at the end of this regime reaches $\psi_{\text {air }}^{\max }=0.34$. Here we assume that the amount of protein at the interface is constant and equal to its value at the transition from regime I to regime II, while further protein adsorption should contribute in this regime according to drop washing test. $\Delta \psi_{\text {air }}^{\max }$ is thus presumably underestimated. However, this value can be compared to the proportion of hydrophobic residues in gliadin sequences that is about one third.

An alternative model is to suppose that the refractive index of the protein interfacial film becomes anisotropic, due to the alignment of the proteins in the film. Such alignment seems realistic considering that gliadins are usually modeled as prolate ellipsoids ${ }^{15}$. This would induce a decrease of $I_{1}$ with the development of anisotropy of the refractive index of the protein layer. According to Equation 7, for one slab dielectric constant profile of the protein film of thickness $h$, equation 7 reads:

$I_{1}=\left[\frac{\left(n_{\perp}^{2}-n_{\text {air }}^{2}\right)\left(n_{\perp}^{2}-n_{\text {bulk }}^{2}\right)}{n_{\perp}^{2}}+\Delta\left(n^{2}\right)\right] h$

Here $\Delta\left(n^{2}\right)=n_{\|}^{2}-n_{\perp}^{2}$, where $n_{\perp}$ (resp. $n_{\|}$) is the index of refraction of the protein layer orthogonal to (resp. in the plane of) the film. Considering $\phi_{L}=0.6$ and $h=4 \mathrm{~nm}$ (the numerical values found at the end of regime I), and a constant index of refraction perpendicular to the film $n_{\perp}$ equal to the index of refraction of gliadin solution at $\phi_{L}=0.6\left(n_{\perp}=1.46\right)$, we estimate that $\Delta\left(n^{2}\right)$ continuously decreases in regime II and reaches a value $\Delta\left(n^{2}\right)^{\max }=-0.0625$, or equivalently $\Delta n^{\max }=n_{\perp}-n_{\|}^{\max }=-0.02$ at the end of regime II. Assuming $\phi_{L}$ constant in this regime, instead of increasing, may underestimate the latter value. However, the order of magnitude appears reasonable in comparison with measurements obtained for flagellin proteins on a hydrophobic surface by optical waveguide light mode spectroscopy $(\Delta n=-$ $0.015)^{31}$. Finally, in regime III, the value of $I_{1}$ is roughly constant indicating that the interfacial optical profile is not modified by the increase of interfacial pressure.

\subsection{Interfacial regimes}

To summarize, the dynamical properties distinguish three main regimes (hereafter referred to as regimes I, II and III) while optical properties reveal a preliminary regime in addition. 
In the preliminary regime (regime 0 ) ellipsometry data show that proteins start to adsorb. However, a null surface pressure is measured. The negligible surface pressure indicates that proteins are in a very dilute regime at the air-water interface. This regime occurs during the so-called induction time of tensiometry kinetics $^{32}$ and can only be observed with the lowest bulk concentration $(0.001 \mathrm{~g} / \mathrm{L})$.

In regime $\mathrm{I}, 0<\Pi<19 \mathrm{mN} / \mathrm{m}$, proteins continue to adsorb but progressively start to interact with each other at the interface as probed by the linear increase of surface concentration and dilatational elasticity with the surface pressure. Dilatational viscoelastic master curves with a similar regime were previously described in different studies ${ }^{3 \mathrm{~b}, 33}$. Interestingly, the behavior of gliadin displays similarities with that of soft proteins like $\beta$-casein. Indeed, the maximum value of $E$ ' at the transition between regimes I and II is relatively weak $(26 \mathrm{mN} / \mathrm{m})$, and comparable to that measured for $\beta$-casein at an air/water interface $(20-30 \mathrm{mN} / \mathrm{m})^{34}$, whereas larger values (typically $70-80 \mathrm{mN} / \mathrm{m}$ ) were reported for several globular/hard proteins ${ }^{3 \mathrm{~b}}$. In addition, the proportionality constant between $E^{\prime}$ and $\Pi$ (i.e. the slope of the $E^{\prime}$ vs $\Pi$ plot) is quite small (approximately 1). According to polymer scaling laws, this low value would be associated to the weak compactness of proteins at interface $\mathrm{e}^{3 \mathrm{c}, 34}$. This weak compactness would induce soft rearrangements of proteins at the interface that are in line with the model of Lucassen-Reynders $e t a l^{3 \mathrm{~b}}$. In this model, proteins are assumed to be able to adopt smaller molecular area with increasing surface pressure, a wider range of conformations being adopted by soft proteins that are more compressible because of their flexible structures. In addition, it was previously demonstrated by a polarization modulation infrared reflection absorption spectroscopy (PM-IRRAS) study that, at the air-water interface, gliadins, which are initially weakly folded and flatly oriented at low surface pressure, progressively fold and orientate their secondary structures as surface pressure increases ${ }^{35}$.

In regime II, $19<\Pi<31 \mathrm{mN} / \mathrm{m}$, a master curve can be plotted with viscoelastic data, even if the maximum of $E$ '' $E$ ' slightly increases with the bulk concentration. This behavior, analogous to the one observed for $\beta$-lactoglobulin 33 c, f can be attributed to the fast interfacial adsorption of proteins with high bulk concentration that would result in more disordered films, more prompt to relax with the oscillatory dilatational stress. The general increase of dilatational dissipative viscoelastic properties associated with an anomalous pressure dependence of the optical profile suggests a significant change of protein conformation. In the literature ${ }^{33 c, 34,36}$, the decrease of $E^{\prime}$ is associated to relaxation processes. Different processes are proposed: reorientation, internal reconformation (formation of loops in the bulk or in air, are specific cases of reconformation), phase transition, formation of 3D structures at the interface, collapse. However, it is very difficult to experimentally prove the exact physical processes involved in the relaxation. In our work, thanks to the combination of different techniques we are able to discard the formation of multilayer and loops in the bulk subphase and their collapse as possible processes. We propose two models to rationalize our ellipsometric data, assuming either a progressive dehydration of the 
proteins as water is not a good solvent for gliadin or the development of anisotropy for the protein refractive index resulting from the anisotropic shape of gliadin protein ${ }^{15,37}$. Both processes were previously identified for several proteins at the air water interface by neutron or X-ray reflectivity ${ }^{38}$. Even if the numerical values obtained with the reorientation model seem more realistic that those obtained with the partial dehydration model, we expect that a more complex behavior involving both phenomena might occur. Overall, our experimental data demonstrate that significant conformational changes occur in regime II, induced by the surface pressure, due to thermodynamics ${ }^{39}$.

Both regimes I and II are related to a protein mass transfer from the bulk to the interface that is controlled by diffusion. By contrast, in regime III, $\Pi>31 \mathrm{mN} / \mathrm{m}$, no protein adsorption is required to induce the surface pressure evolution. In addition, a drastic increase of the elastic modulus $E$ ' with $\Pi$ is measured, signing the increasing incompressibility of the interfacial film, while a constant optical profile is observed. We attribute this regime to ageing of the protein film at the air-water interface. A modification of interactions inside the protein film with time can be at the origin of the behavior observed. Gelation phenomena could occur but interfacial shear rheology would be required to fully characterize it.

The sequence of three regimes, adsorption-reorganization-gelation, was previously proposed for different proteins at interfaces ${ }^{40}$. However, generally the shape of dynamic interfacial tension displays only one decay step. The induction time (during which surface pressure $\Pi \approx 0$ ) was associated to protein adsorption, the steep increase of surface pressure with time being associated to protein relaxation and the final slow increase of surface pressure being associated to gelation. This interpretation was only based on surface tension measurements and quite speculative while the combination of techniques used in our study gives more credit to our interpretation. Note finally that three comparable regimes were previously identified for gliadins in the bulk ${ }^{9}$. Upon osmotic compression, after a dilute regime of repulsive colloids, a highly compressible regime with secondary structure changes was evidenced, and followed by a regime of strongly interacting proteins.

\section{Conclusion}

We have studied the adsorption of gliadin proteins at the air-water interface from acidic protein solutions over a broad range of concentrations. Combination of dilatational viscoelastic measurements and optical profile measurements provides a consistent physical picture of the three steps process, as summarized in Figure 7 . In the preliminary regime (regime 0 , not represented), the surface pressure is equal to zero and proteins start to adsorb on a very dilute interface. Then, in the first regime, at small surface pressure $\Pi$ (regime I), the ellipsometric signal $I_{1}$ and the elastic modulus $E^{\prime}$ increase with the surface pressure, while 
the loss modulus $E$ " remains small. This regime corresponds to a progressive coverage of the interface by individual weakly interacting flexible proteins, up to a critical surface pressure $\Pi_{\mathrm{c} 1}$. The second regime $\left(\Pi_{\mathrm{c} 1}<\Pi<\Pi_{\mathrm{c} 2}\right)$ results from significant conformational rearrangements of the protein film induced by further protein adsorption, which are identified by a strong increase of the dissipative viscoelastic properties of the film concomitantly with an anomalous evolution of its optical profile. Finally, in regime III $\left(\Pi>\Pi_{\mathrm{c} 2}\right)$, the ellipsometric signal does not evolve with the surface pressure, suggesting that the structure of the interfacial layer does not change significantly. In this regime, on the other hand, a dramatic increase of the elastic modulus is measured while no further adsorption occurs. The two experimental observations can be consistently interpreted as resulting from ageing of the interfacial layer.

The softness of gliadins, which we have evidenced at the air/water interface, is presumably linked to its partially disordered secondary structure due to the abundance of proline and glycin residues in the repetitive domains of their primary sequence. This behavior could be associated to the biological function of these proteins that is to store amino-acid for the future development of the plant in the wheat grain. An efficient accumulation of proteins in a minimum volume should be reached thanks to their capacity to reorganize with an increasing osmotic pressure. Furthermore, from an industrial point of view, the gliadin softness is a clear asset as it should limit emulsion drop breakup in shear flow as demonstrated for a model flexible protein by Erni et $\mathrm{al}^{41}$.

\section{Acknowledgments}

This work was performed, in partnership with the SAS PIVERT, within the frame of the French Institute for the Energy Transition (ITE P.I.V.E.R.T., www.institut-pivert.com) selected as an Investment for the Future by the French Government under the reference ANR-001-01.We thank Marie-Hélène Morel for the development of gliadin extraction and the HPLC measurements. We also acknowledge the Laboratory of Excellence NUMEV (ANR-10-LAB-20) for partial funding of the Brewster Angle Microscope. 

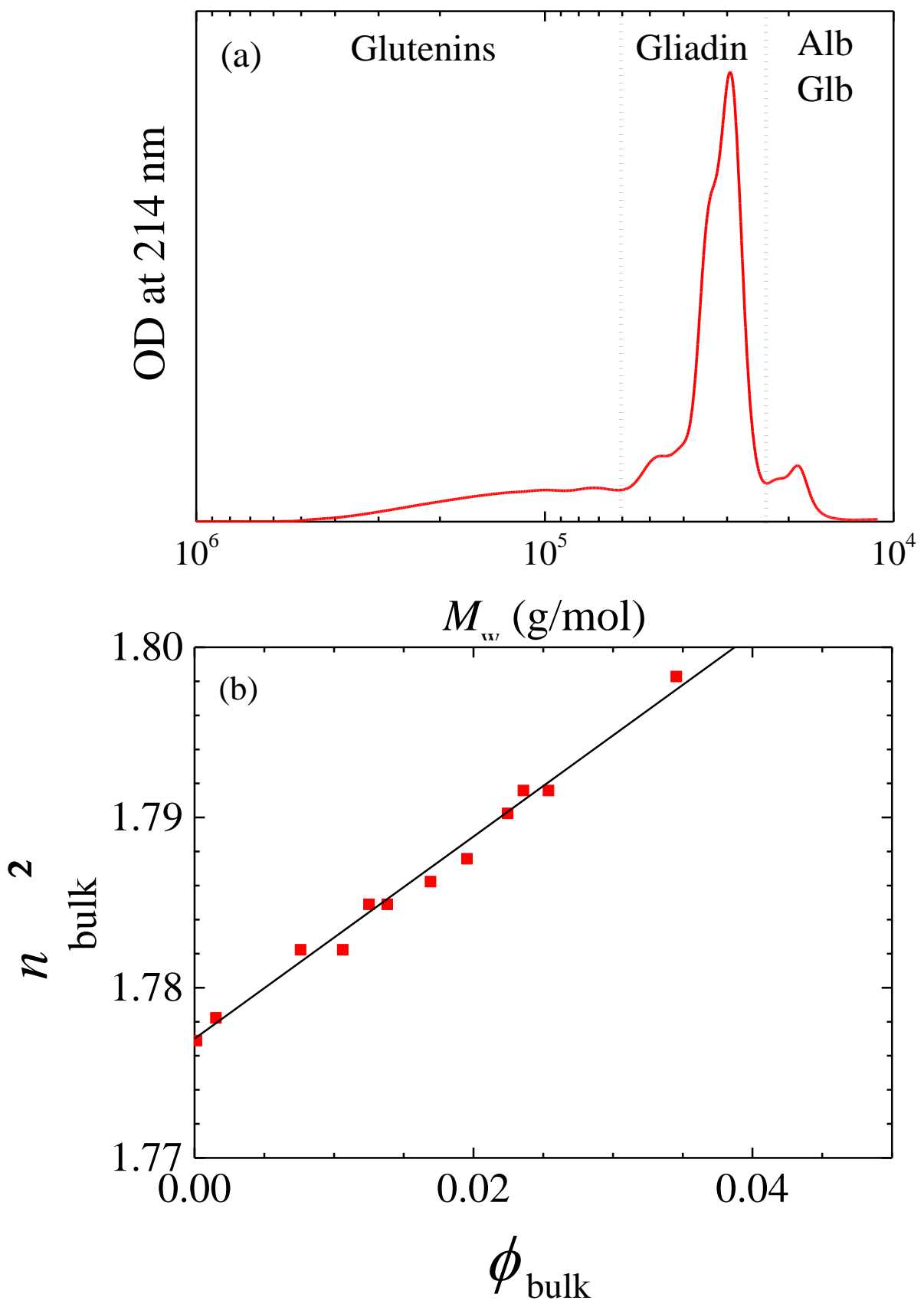

Figure 1: Characterization of the protein extract. (a) Size-exclusion high performance liquid chromatography (SE-HPLC) profile of the gliadin extract. The dashed lines delineate the molecular weight $\left(M_{\mathrm{w}}\right)$ limits for albumin (alb) and globulin (glob) $\left(M_{\mathrm{w}}<23000 \mathrm{~g} / \mathrm{mol}\right)$, for gliadin $(23000 \mathrm{~g} / \mathrm{mol}<$ $\left.M_{\mathrm{w}}<60000 \mathrm{~g} / \mathrm{mol}\right)$ and for glutenin $\left(M_{\mathrm{w}}>60000 \mathrm{~g} / \mathrm{mol}\right)$. (b) Variation of the square of the refractive index of gliadin solutions as a function of the protein volume fraction. The line is a linear fit of the experimental data points. 


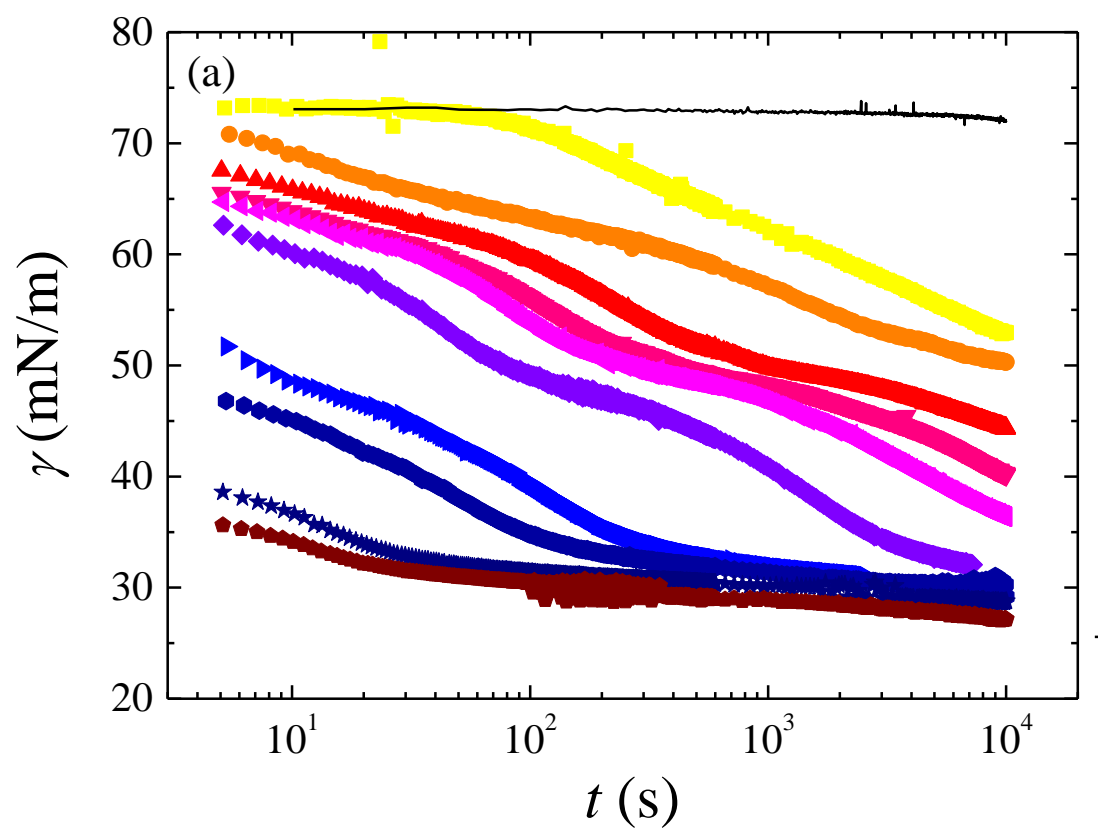

$0.01 \mathrm{~g} / \mathrm{L}$

- $0.1 \mathrm{~g} / \mathrm{L}$

- $0.25 \mathrm{~g} / \mathrm{L}$

$\checkmark 0.5 \mathrm{~g} / \mathrm{L}$

4 $0.75 \mathrm{~g} / \mathrm{L}$

- $1 \mathrm{~g} / \mathrm{L}$

- $5 \mathrm{~g} / \mathrm{L}$

- $11 \mathrm{~g} / \mathrm{L}$

* 46g/L

- $110 \mathrm{~g} / \mathrm{L}$ solvent
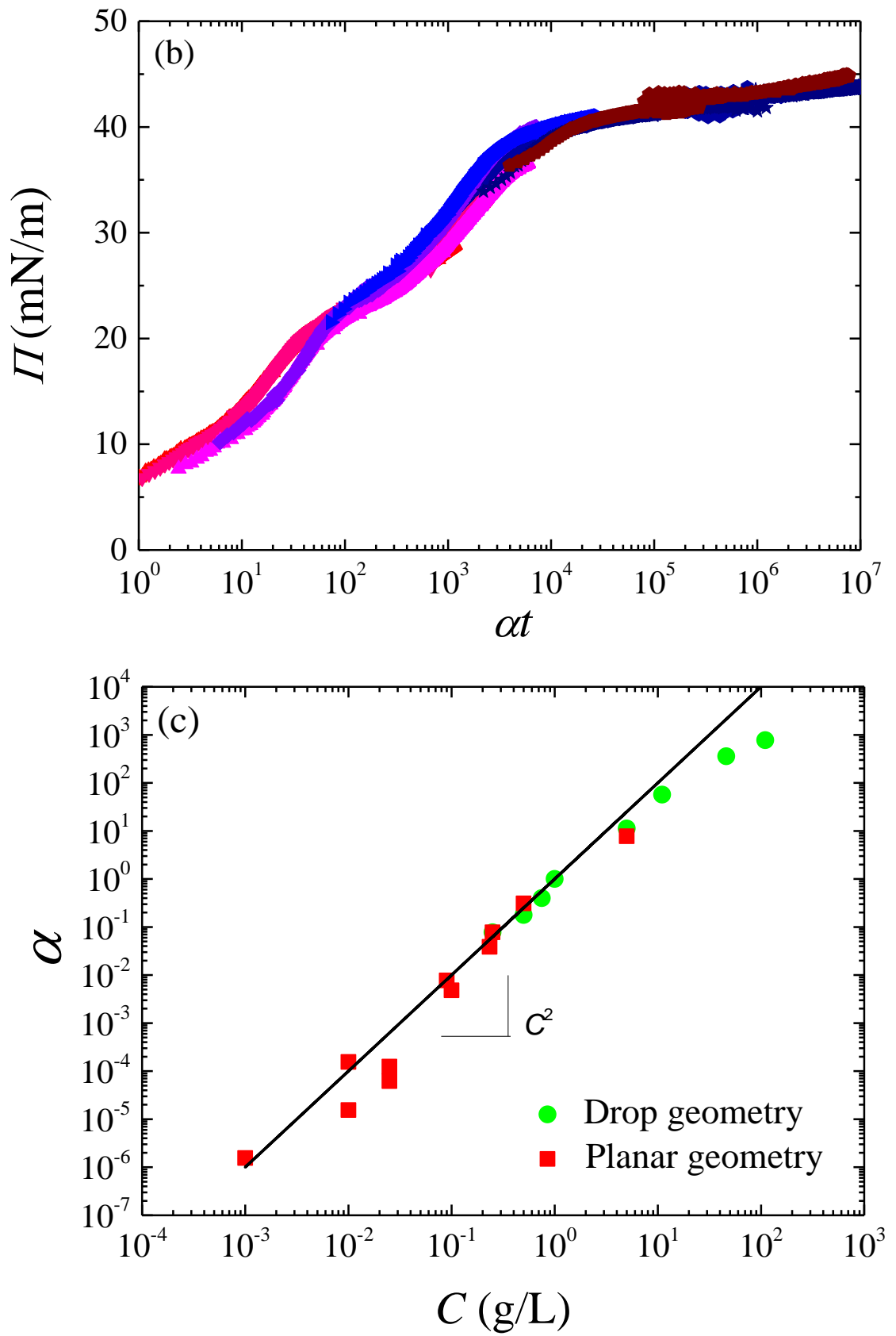
Figure 2: (a) Time evolution of the surface tension for the solvent (thin black line) and for protein solutions at different protein concentrations $C$ as indicated in the legend. Experiments were performed using the pendant drop tensiometer (drop geometry) (b) Master curve obtained by plotting the surface pressure as a function of a normalized time, $\alpha t$, using $C=1 \mathrm{~g} / \mathrm{L}$ as reference. All data except the two smallest concentrations (0.01 and $0.1 \mathrm{~g} / \mathrm{L})$ are shown. Symbols are the same as in (a). (c) Scale factor, $\alpha$, as a function of protein concentration for measurements performed with drop and plane geometries. The line is the theoretical expectation for a diffusive process (Eq. 16). 


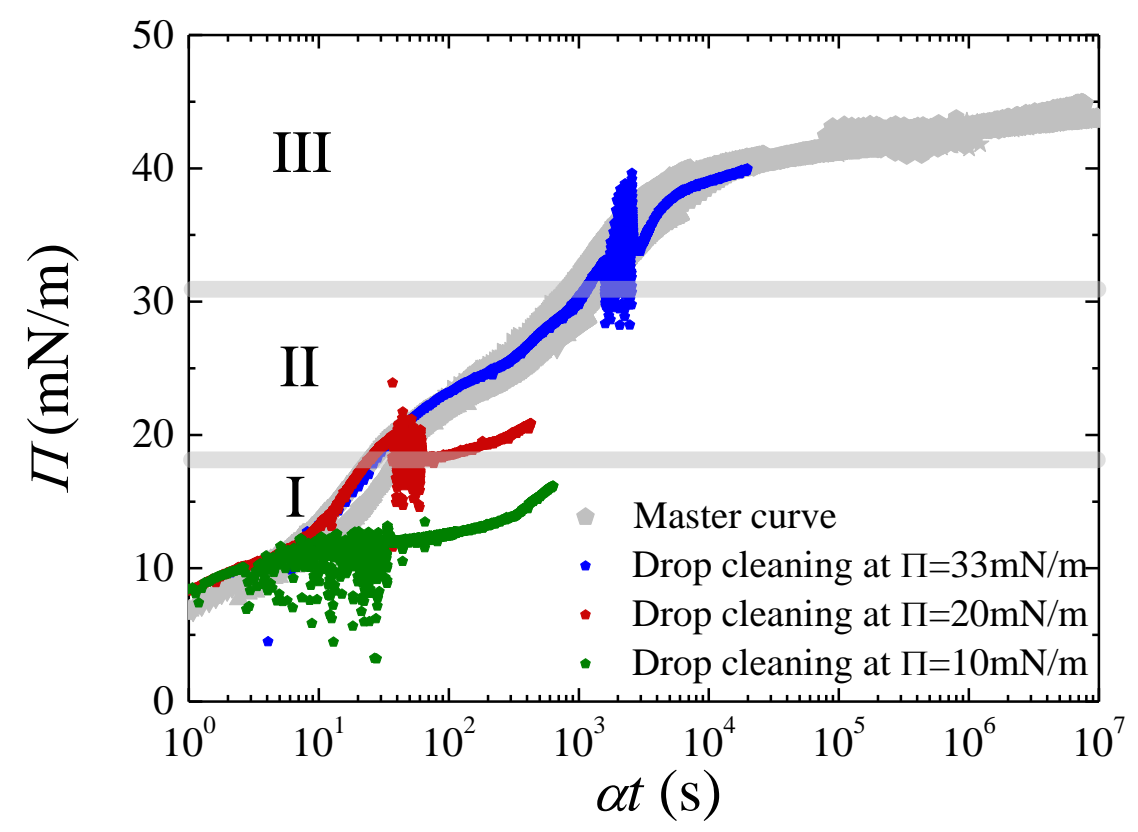

Figure 3: Surface pressure as a function of the normalized time, $\alpha$. The gray data points correspond to the master curve shown in Fig. 2b. The colored symbols correspond to experiments where the interior of the drop has been washed at different surface pressures as indicated in the caption. The gray horizontal lines display the limits $\left(\Pi_{\mathrm{c} 1}\right.$ and $\left.\Pi_{\mathrm{c} 2}\right)$ of the different regimes identified by dilatational viscoelasticity and ellipsometry experiments. 


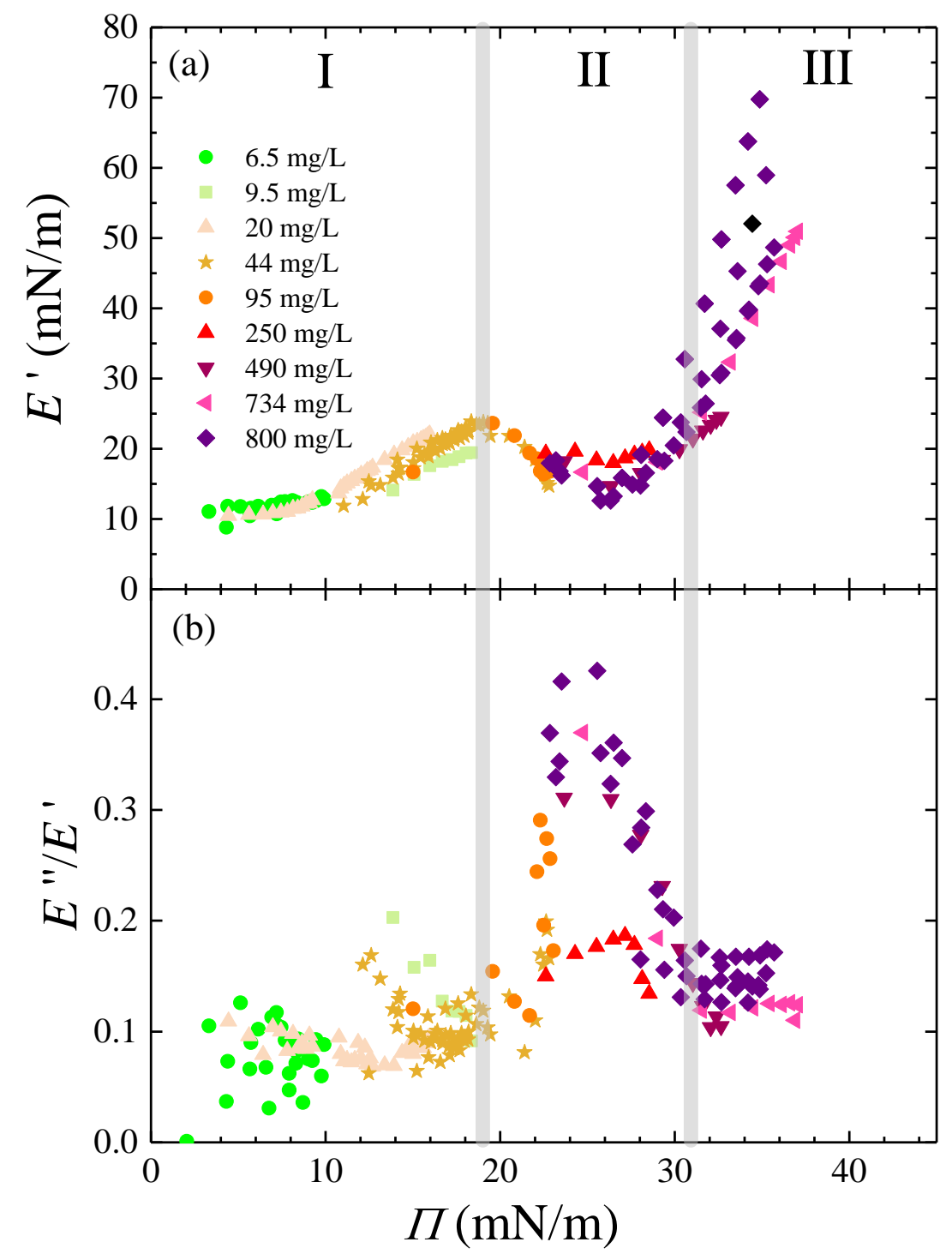

Figure 4: Dilatational elastic modulus $E^{\prime}$ (a) and ratio between the viscous and elastic moduli, E'/E' (b) as a function of the surface pressure $\Pi$, for different protein concentrations as indicated in the legend. Thick gray lines delineate 3 regimes with cross-overs at $\Pi_{\mathrm{c} 1}$ and $\Pi_{\mathrm{c} 2}$. 

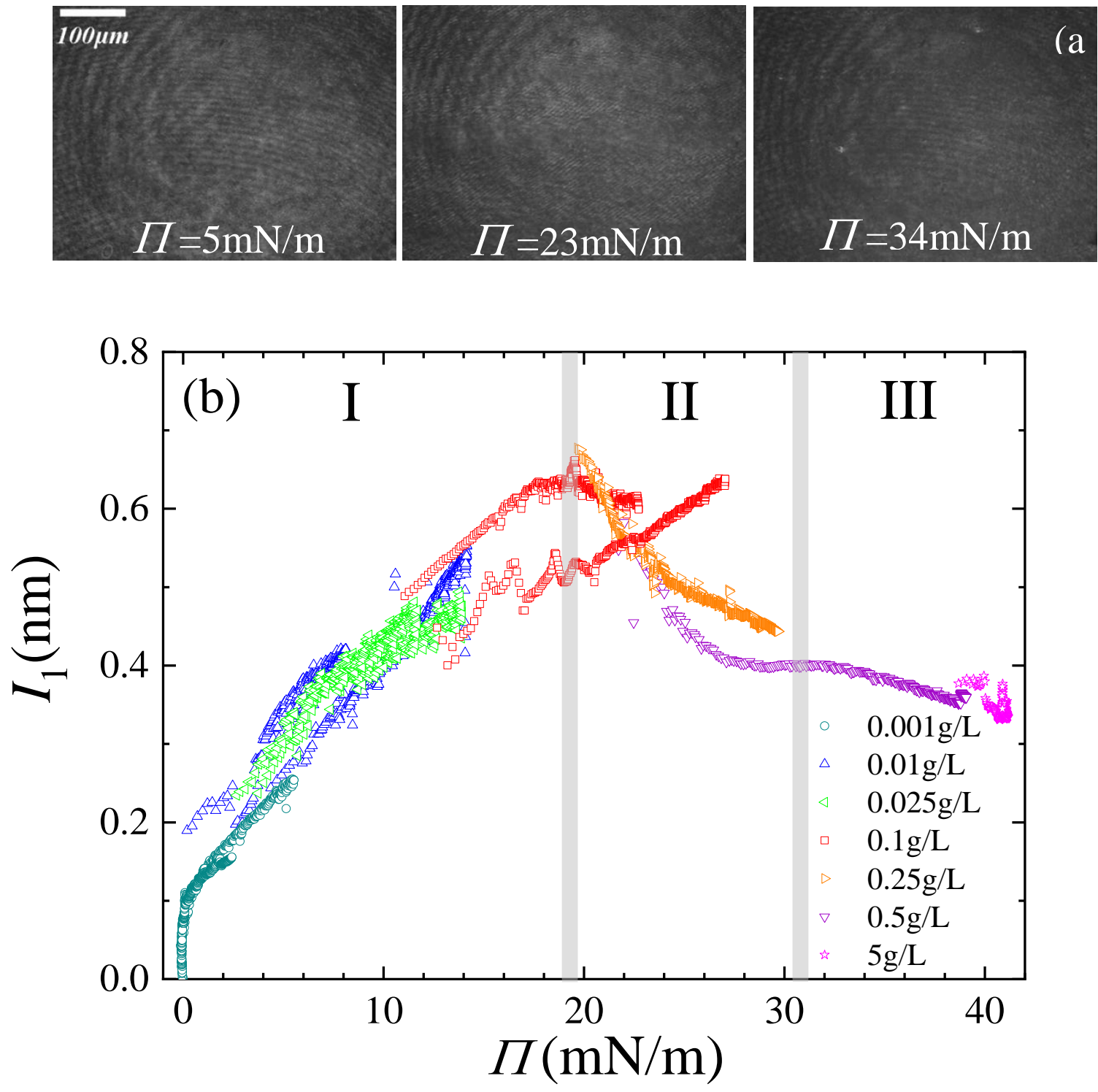

Figure 5: (a) Typical Brewster angle microscopy images of the planar interface taken in the three regimes. From left to right, the polarizer angle is $5^{\circ}, 10^{\circ}$ and $15^{\circ}$. (b) Ellipsometric response, $I_{1}$, as a function of the surface pressure, $\Pi$, for different protein concentrations as indicated in the legend. Thick gray lines delineate the 3 regimes with cross-overs at $\Pi_{\mathrm{c} 1}$ and $\Pi_{\mathrm{c} 2}$. 

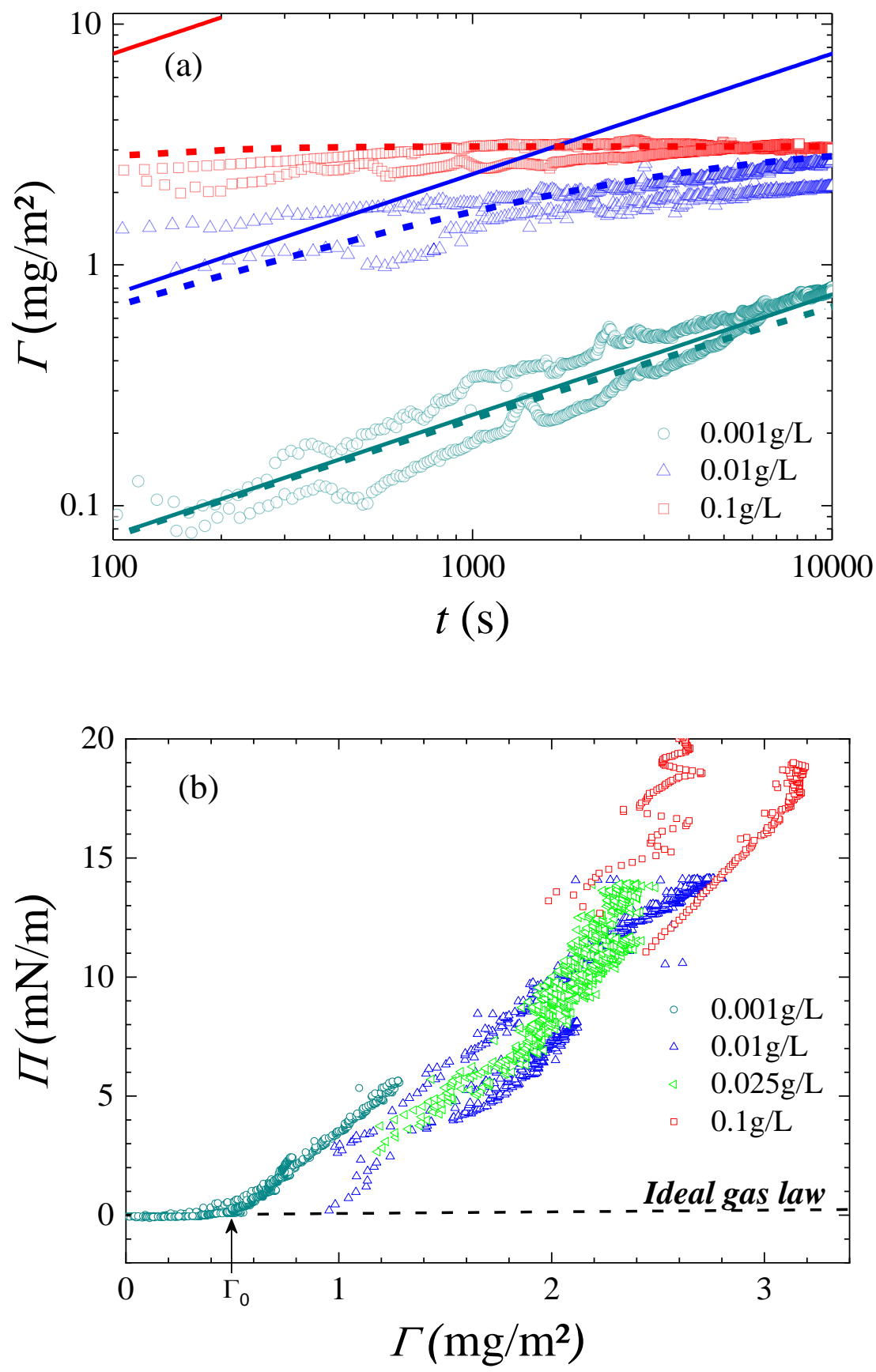

Figure 6: (a) Surface excess concentration $\Gamma$ as a function of time $t$. Symbols correspond to experimental data obtained by ellipsometry for different protein bulk concentrations as indicated in the caption. Dashed and continuous lines display diffusive models expressed in Equations 11 and 12 respectively. (b) Equation of state, surface pressure as a function of the surface excess concentration, in regime I. 
PROTEIN ADSORPTION

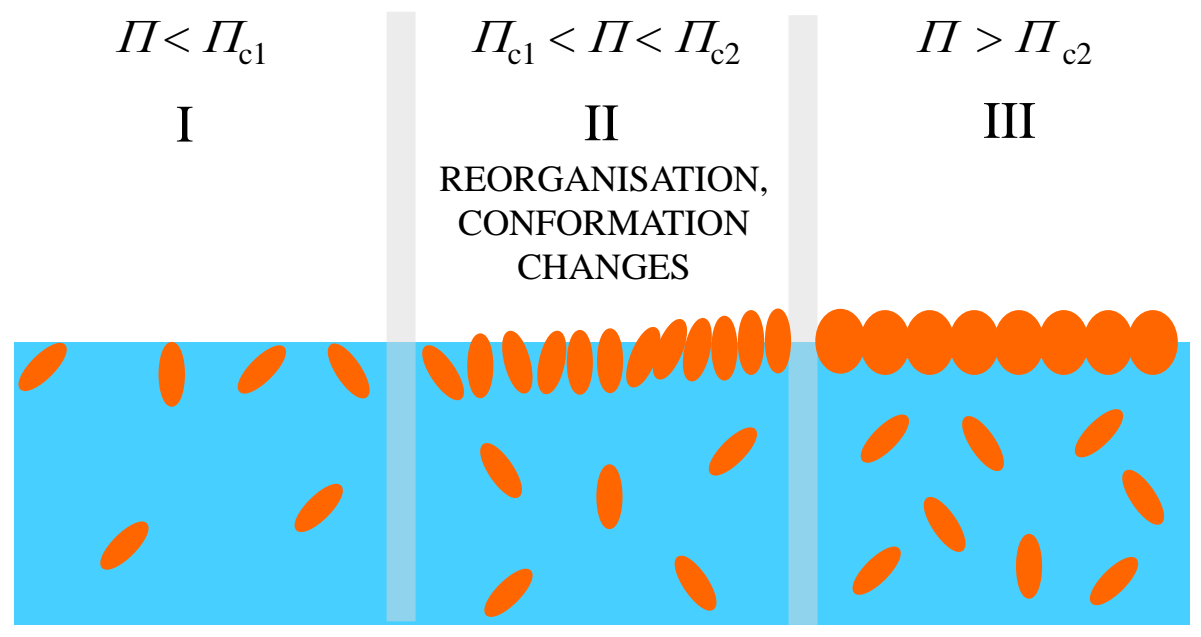

Figure 7: Scheme of the three interfacial regimes identified thanks to structural and rheological measurements of the gliadin air/water interface. The three regimes are defined by the interfacial pressure. 


\section{References}

1. Langevin, D., Influence of interfacial rheology on foam and emulsion properties. Adv Colloid Interfac 2000, 88 (1-2), 209-222.

2. Dickinson, E., Adsorbed protein layers at fluid interfaces: interactions, structure and surface rheology. Colloid Surface B 1999, 15 (2), 161-176.

3. (a) Bos, M. A.; van Vliet, T., Interfacial rheological properties of adsorbed protein layers and surfactants: a review. Adv Colloid Interfac 2001, 91 (3), 437-471; (b) Lucassen-Reynders, E. H.; Benjamins, J.; Fainerman, V. B., Dilational rheology of protein films adsorbed at fluid interfaces. Curr Opin Colloid In 2010, 15 (4), 264-270; (c) Douillard, R.; Daoud, M.; Aguie-Beghin, V., Polymer thermodynamics of adsorbed protein layers. Curr Opin Colloid In 2003, 8 (4-5), 380-386.

4. (a) Ducel, V.; Richard, J.; Popineau, Y.; Boury, F., Adsorption kinetics and rheological interfacial properties of plant proteins at the oil-water interface. Biomacromolecules 2004, 5 (6), 2088-2093; (b) Wang, J. M.; Xia, N.; Yang, X. Q.; Yin, S. W.; Qi, J. R.; He, X. T.; Yuan, D. B.; Wang, L. J., Adsorption and Dilatational Rheology of Heat-Treated Soy Protein at the Oil-Water Interface: Relationship to Structural Properties. J Agr Food Chem 2012, 60 (12), 3302-3310; (c) Berecz, B.; Mills, E. N. C.; Tamas, L.; Lang, F.; Shewry, P. R.; Mackie, A. R., Structural Stability and Surface Activity of Sunflower 2 S Albumins and Nonspecific Lipid Transfer Protein. J Agr Food Chem 2010, 58 (10), 6490-6497; (d) Patino, J. M. R.; Sanchez, C. C.; Ortiz, S. E. M.; Nino, M. R. R.; Anon, M. C., Adsorption of soy globulin films at the air-water interface. Ind Eng Chem Res 2004, 43 (7), 1681-1689.

5. Ornebro, J.; Nylander, T.; Eliasson, A. C., Interfacial behaviour of wheat proteins. J Cereal Sci 2000, 31 (2), 195-221.

6. Tschoegl, N. W. a. A., A. E., The surface chemistry of wheat gluten II. Measurements of surface viscoelasticity. Journal of Colloid Science 1960, 15 (2), 168-182.

7. Dahesh, M.; Banc, A.; Duri, A.; Morel, M. H.; Ramos, L., Polymeric Assembly of Gluten Proteins in an Aqueous Ethanol Solvent. J Phys Chem B 2014, 118 (38), 11065-11076.

8. Georget, D. M. R.; Belton, P. S., Effects of temperature and water content on the secondary structure of wheat gluten studied by FTIR spectroscopy. Biomacromolecules 2006, 7 (2), 469-475.

9. Boire, A.; Menut, P.; Morel, M. H.; Sanchez, C., Osmotic Compression of Anisotropic Proteins: Interaction Properties and Associated Structures in Wheat Gliadin Dispersions. J Phys Chem B 2015, 119 (17), 5412-5421.

10. (a) Mita, T.; Nikai, K.; Hiraoka, T.; Matsuo, S.; Matsumoto, H., Physicochemical Studies on Wheat-Protein Foams. J Colloid Interf Sci 1977, 59 (1), 172-178; (b) Keller, R. C. A.; Orsel, R.; Hamer, R. J., Competitive adsorption behaviour of wheat flour components and emulsifiers at an air-water interface. J Cereal Sci 1997, 25 (2), 175-183.

11. Bos, M. A.; Dunnewind, B.; van Vliet, T., Foams and surface rheological properties of betacasein, gliadin and glycinin. Colloid Surface B 2003, 31 (1-4), 95-105.

12. Takeda, K.; Matsumura, Y.; Shimizu, M., Emulsifying and surface properties of wheat gluten under acidic conditions. J Food Sci 2001, 66 (3), 393-399.

13. (a) Peng, D. F.; Jin, W. P.; Li, J.; Xiong, W. F.; Pei, Y. Q.; Wang, Y. T.; Li, Y.; Li, B., Adsorption and Distribution of Edible Gliadin Nanoparticles at the Air/Water Interface. J Agr Food Chem 2017, 65 (11), 2454-2460; (b) Thewissen, B. G.; Celus, I.; Brijs, K.; Delcour, J. A., Foaming Properties of Wheat Gliadin. J Agr Food Chem 2011, 59 (4), 1370-1375.

14. Dahesh, M.; Banc, A.; Duri, A.; Morel, M. H.; Ramos, L., Spontaneous gelation of wheat gluten proteins in a food grade solvent. Food Hydrocolloid 2016, 52, 1-10.

15. Thomson, N. H.; Miles, M. J.; Popineau, Y.; Harries, J.; Shewry, P.; Tatham, A. S., Small angle $\mathrm{X}$-ray scattering of wheat seed-storage proteins: alpha-, gamma- and omega-gliadins and the high molecular weight (HMW) subunits of glutenin. Bba-Protein Struct M 1999, 1430 (2), 359-366. 
16. Zhang, Z.; Scanlon, M. G., Solvent effects on the molecular structures of crude gliadins as revealed by density and ultrasound velocity measurements. J Cereal Sci 2011, 54 (2), 181-186.

17. Aspnes, D. E., Optical-Properties of Thin-Films. Thin Solid Films 1982, 89 (3), 249-262.

18. Robertson, T. B.; Greaves, J. E., On the refractive indices of solutions of certain proteins. V. Gliadin. J Biol Chem 1911, 9 (3), 181-184.

19. Loglio, G. P., P.; Miller, R.; Makievski, A.V.; Ravera, F.; Ferrari, M.; Liggieri, L., Drop and bubble shape analysis as tool for dilatational rheology of interfacial layers. In Novel Methods to Study Interfacial Layers, D. Möbius, R. M., Ed. Elsevier: 2001.

20. Lekner, J., Theory of Reflection. Springer Netherlands: Dordrecht, The Netherlands, 1987.

21. (a) Stocco, A.; Tauer, K.; Pispas, S.; Sigel, R., Dynamics of amphiphilic diblock copolymers at the air-water interface. J Colloid Interf Sci 2011, 355 (1), 172-178; (b) Ramirez, P.; Stocco, A.; Munoz, J.; Miller, R., Interfacial rheology and conformations of triblock copolymers adsorbed onto the water-oil interface. J Colloid Interf Sci 2012, 378, 135-143.

22. Kairaliyeva, T.; Aksenenko, E. V.; Mucic, N.; Makievski, A. V.; Fainerman, V. B.; Miller, R., Surface Tension and Adsorption Studies by Drop Profile Analysis Tensiometry. J Surfactants Deterg 2017, 20 (6), 1225-1241.

23. Ferri, J. K.; Gorevski, N.; Kotsmar, C.; Leser, M. E.; Miller, R., Desorption kinetics of surfactants at fluid interfaces by novel coaxial capillary pendant drop experiments. Colloid Surface A 2008, 319 (1-3), 13-20.

24. (a) Freer, E. M.; Yim, K. S.; Fuller, G. G.; Radke, C. J., Interfacial rheology of globular and flexible proteins at the hexadecane/water interface: Comparison of shear and dilatation deformation. $J$ Phys Chem B 2004, 108 (12), 3835-3844; (b) Mitropoulos, V.; Mutze, A.; Fischer, P., Mechanical properties of protein adsorption layers at the air/water and oil/water interface: A comparison in light of the thermodynamical stability of proteins. Adv Colloid Interfac 2014, 206, 195-206; (c) Graham, D. E.; Phillips, M. C., Proteins at Liquid Interfaces .1. Kinetics of Adsorption and Surface Denaturation. $J$ Colloid Interf Sci 1979, 70 (3), 403-414.

25. Miura, T.; Seki, K., Diffusion Influenced Adsorption Kinetics. J Phys Chem B 2015, 119 (34), 10954-10961.

26. Douglas, J. F.; Johnson, H. E.; Granick, S., A Simple Kinetic-Model of Polymer Adsorption and Desorption. Science 1993, 262 (5142), 2010-2012.

27. Langmuir, I.; Schaefer, V. J., The effect of dissolved salts on insoluble monolayers. J Am Chem Soc 1937, 59, 2400-2414.

28. Ward, A. F. H.; Tordai, L., Time-Dependence of Boundary Tensions of Solutions .1. The Role of Diffusion in Time-Effects. J Chem Phys 1946, 14 (7), 453-461.

29. (a) Ybert, C.; di Meglio, J. M., Study of protein adsorption by dynamic surface tension measurements: Diffusive regime. Langmuir 1998, 14 (2), 471-475; (b) Hansen, F. K.; Myrvold, R., The kinetics of albumin adsorption to the air/water interface measured by automatic axisymmetric drop shape analysis. J Colloid Interf Sci 1995, 176 (2), 408-417; (c) Paulsson, M.; Dejmek, P., Surface-Film Pressure of Beta-Lactoglobulin, Alpha-Lactalbumin and Bovine Serum-Albumin at the Air-Water-Interface Studied by Wilhelmy Plate and Drop Volume. J Colloid Interf Sci 1992, 150 (2), 394-403.

30. Miura, T.; Seki, K., Effects of surface affinity on the ordering dynamics of self-assembled monolayers of chain molecules: Transition from a parallel to a perpendicular structure. Phys Rev E 2015, $91(5)$.

31. Kovacs, N.; Patko, D.; Orgovan, N.; Kurunczi, S.; Ramsden, J. J.; Vonderviszt, F.; Horvath, R., Optical Anisotropy of Flagellin Layers: In Situ and Label-Free Measurement of Adsorbed Protein Orientation Using OWLS. Anal Chem 2013, 85 (11), 5382-5389.

32. Miller, R.; Fainerman, V. B.; Aksenenko, E. V.; Leser, M. E.; Michel, M., Dynamic surface tension and adsorption kinetics of beta-casein at the solution air interface. Langmuir 2004, 20 (3), 771777.

33. (a) Benjamins, J.; Cagna, A.; LucassenReynders, E. H., Viscoelastic properties of triacylglycerol/water interfaces covered by proteins. Colloid Surface A 1996, 114, 245-254; (b) 
Benjamins, J.; Reynders, E. H. L., Static and dynamic properties of proteins adsorbed at three different liquid interfaces. Roy Soc Ch 2003, (284), 216-225; (c) Benjamins, J.; Lyklema, J.; Lucassen-Reynders, E. H., Compression/expansion rheology of oil/water interfaces with adsorbed proteins. Comparison with the air/water surface. Langmuir 2006, 22 (14), 6181-6188; (d) Miller, R.; Ferri, J. K.; Javadi, A.; Kragel, J.; Mucic, N.; Wustneck, R., Rheology of interfacial layers. Colloid Polym Sci 2010, 288 (9), 937-950; (e) Ulaganathan, V.; Retzlaff, I.; Won, J. Y.; Gochev, G.; Gunes, D. Z.; Gehin-Delval, C.; Leser, M.; Noskov, B. A.; Miller, R., beta-Lactoglobulin adsorption layers at the water/air surface: 2. Dilational rheology: Effect of $\mathrm{pH}$ and ionic strength. Colloid Surface A 2017, 521, 167-176.

34. Cicuta, P.; Hopkinson, I., Studies of a weak polyampholyte at the air-buffer interface: The effect of varying $\mathrm{pH}$ and ionic strength. $J$ Chem Phys 2001, 114 (19), 8659-8670.

35. Banc, A.; Desbat, B.; Renard, D.; Popineau, Y.; Mangavel, U.; Navailles, L., Structure and orientation changes of omega- and gamma-gliadins at the air-water interface: A PM-IRRAS Spectroscopy and Brewster angle microscopy study. Langmuir 2007, 23 (26), 13066-13075.

36. Hambardzumyan, A.; Aguie-Beghin, V.; Daoud, M.; Douillard, R., beta-casein and symmetrical triblock copolymer (PEO-PPO-PEO and PPO-PEO-PPO) surface properties at the air-water interface. Langmuir 2004, 20 (3), 756-763.

37. Ang, S.; Kogulanathan, J.; Morris, G. A.; Kok, M. S.; Shewry, P. R.; Tatham, A. S.; Adams, G. G.; Rowe, A. J.; Harding, S. E., Structure and heterogeneity of gliadin: a hydrodynamic evaluation. Eur Biophys J Biophy 2010, 39 (2), 255-261.

38. (a) Lu, J. R.; Su, T. J.; Thomas, R. K.; Penfold, J.; Webster, J., Structural conformation of lysozyme layers at the air/water interface studied by neutron reflection. J Chem Soc Faraday T 1998, 94 (21), 3279-3287; (b) Tucker, I. M.; Petkov, J. T.; Penfold, J.; Thomas, R. K.; Cox, A. R.; Hedges, N., Adsorption of Hydrophobin-Protein Mixtures at the Air-Water Interface: The Impact of $\mathrm{pH}$ and Electrolyte. Langmuir 2015, 31 (36), 10008-10016; (c) Lu, J. R.; Perumal, S.; Zhao, X. B.; Miano, F.; Enea, V.; Heenan, R. R.; Penfold, J., Surface-induced unfolding of human lactoferrin. Langmuir 2005, 21 (8), 3354-3361; (d) Yano, Y. F.; Kobayashi, Y.; Ina, T.; Nitta, K.; Uruga, T., Hofmeister Anion Effects on Protein Adsorption at an Air-Water Interface. Langmuir 2016, 32 (38), 9892-9898.

39. Joos, P.; Serrien, G., The Principle of Braun-Le Chatelier at Surfaces. J Colloid Interf Sci 1991, 145 (1), 291-294.

40. Beverung, C. J.; Radke, C. J.; Blanch, H. W., Protein adsorption at the oil/water interface: characterization of adsorption kinetics by dynamic interfacial tension measurements. Biophys Chem 1999, 81 (1), 59-80.

41. Erni, P.; Windhab, E. J.; Fischer, P., Emulsion Drops with Complex Interfaces: Globular Versus Flexible Proteins. Macromol Mater Eng 2011, 296 (3-4), 249-262. 